\title{
The Big Vitamin D Mistake
}

\author{
Dimitrios T. Papadimitriou ${ }^{1,2}$ \\ ${ }^{1}$ Third Department of Pediatrics, Division of Pediatric Endocrinology, Attikon University Hospital, University of Athens School of Medicine, Athens; \\ ${ }^{2}$ Pediatric-Adolescent Endocrinology and Diabetes, Athens Medical Center, Athens, Greece
}

Since 2006, type 1 diabetes in Finland has plateaued and then decreased after the authorities' decision to fortify dietary milk products with cholecalciferol. The role of vitamin D in innate and adaptive immunity is critical. A statistical error in the estimation of the recommended dietary allowance (RDA) for vitamin $D$ was recently discovered; in a correct analysis of the data used by the Institute of Medicine, it was found that $8895 \mathrm{IU} / \mathrm{d}$ was needed for $97.5 \%$ of individuals to achieve values $\geq 50 \mathrm{nmol} / \mathrm{L}$. Another study confirmed that $6201 \mathrm{lU} / \mathrm{d}$ was needed to achieve $75 \mathrm{nmol} / \mathrm{L}$ and $9122 \mathrm{lU} / \mathrm{d}$ was needed to reach $100 \mathrm{nmol} / \mathrm{L}$. The largest meta-analysis ever conducted of studies published between 1966 and 2013 showed that 25-hydroxyvitamin D levels $<75 \mathrm{nmol} / \mathrm{L}$ may be too low for safety and associated with higher all-cause mortality, demolishing the previously presumed U-shape curve of mortality associated with vitamin D levels. Since all-disease mortality is reduced to 1.0 with serum vitamin D levels $\geq 100 \mathrm{nmol} / \mathrm{L}$, we call public health authorities to consider designating as the RDA at least three-fourths of the levels proposed by the Endocrine Society Expert Committee as safe upper tolerable daily intake doses. This could lead to a recommendation of $1000 \mathrm{IU}$ for children $<1$ year on enriched formula and 1500 IU for breastfed children older than 6 months, $3000 \mathrm{IU}$ for children $>1$ year of age, and around $8000 \mathrm{IU}$ for young adults and thereafter. Actions are urgently needed to protect the global population from vitamin D deficiency.

Key words: Vitamin D deficiency, Recommended dietary allowance, Institute of Medicine, Type 1 diabetes

\section{INTRODUCTION}

The incidence of type 1 diabetes (T1D) has been doubling every 20 years. In Finland, the recommendation for daily vitamin D supplementation was gradually reduced from 40005000 IU in 1964 to 400 IU in 1992. Concomitantly, T1D increased by $350 \%$ in those aged $1-4$ years, $100 \%$ in those aged 5-9 years, and $50 \%$ in those aged 10-14 years [1]. However,

Received: November 18, 2016 Accepted: May 3, 2017

Corresponding author: Dimitrios T. Papadimitriou, MD, PhD

58 Kifissias Ave., Athens 15125, Greece

Tel: +30-210-363-8536, Fax: +30-210-610-6406

E-mail: info@pedoendo.gr

This is an Open Access article distributed under the terms of the Creative Commons Attribution Non-Commercial License (http://creativecommons.org/licenses/by$\mathrm{nc} / 4.0 /$ ) which permits unrestricted non-commercial use, distribution, and reproduction in any medium, provided the original work is properly cited. since 2006, T1D has plateaued and decreased after an increase in serum 25-hydroxyvitamin D (25[OH]D) after the authorities' decision to fortify all dietary milk products with cholecalciferol [2]. Moreover, the worldwide association of ultraviolet (UV)-B light and vitamin D status with T1D and multiple sclerosis is now more than evident.

\section{MAIN BODY}

\section{Vitamin D and Immunomodulation}

The role of vitamin $D$ in innate and adaptive immunity is critical. It has been shown that the redirection of human autoreactive T-cells upon interaction with dendritic cells can be modulated by an analog of 1,25-dihydroxyvitamin $D_{3}$ [3]. In a recent plenary session entitled "Cell Therapy in Type 1 Diabetes" that closed the 2016 meeting of the European Society for 
Paediatric Endocrinology in Paris, Bart O. Roep [3] announced the initiation of phase 1 clinical trials in humans in 2016 with the following protocol: dendritic cells will be isolated from the patient's peripheral blood, cultured with calcitriol, and then re-injected in an abdominal intradermal position to 'teach' the rest of the immune cells not to attack $\beta$-cells anymore. In a large birth cohort study, T1D incidence was reduced by $78 \%$ with $2000 \mathrm{IU}$ of cholecalciferol per day [4]. Moreover, T1D autoantibodies can be "negativated" with oral calcitriol [5]. Vita$\min D$ levels $>100 \mathrm{nmol} / \mathrm{L}(40 \mathrm{ng} / \mathrm{mL}$ with a conversion factor of $\times 2.5$ ) improve insulin secretion [6] and prevent $\beta$-cell destruction by suppressing macrophage adhesion and migration through downregulation of endoplasmic reticulum stress and scavenger receptor-A1 [7].

\section{The Statistical Error in the Estimation of the} Recommended Dietary Allowance of Vitamin D

Veugelers and Ekwaru [8], in a correct reanalysis of the data used by the Institute of Medicine, proved that $8895 \mathrm{IU} / \mathrm{d}$ are needed for $97.5 \%$ of individuals to achieve values $\geq 50 \mathrm{nmol} /$ L. Heaney et al. [9] confirmed that finding, reporting that 6201 IU/d were needed to achieve the Endocrine Society's recommendation of $75 \mathrm{nmol} / \mathrm{L}$ and $9122 \mathrm{IU} /$ day to reach $100 \mathrm{nmol} / \mathrm{L}$.

\section{What Serum Vitamin D Levels Should We Aim for?}

Garland et al. [10] published the largest meta-analysis ever conducted of all studies published between January 1, 1966 and January 15, 2013 dealing with all-cause mortality related to serum $25(\mathrm{OH}) \mathrm{D}$, showing that $25(\mathrm{OH}) \mathrm{D}$ levels $<75 \mathrm{nmol} / \mathrm{L}$ may be too low for safety and associated with higher all-cause mortality, demolishing the U-shape curve of vitamin D levels and mortality that had been assumed until then.

\section{Call to Public Health Authorities}

Since all-disease (autoimmune diseases, metabolic syndrome, type 2 diabetes, cancer) mortality risk is reduced to 1.0 with serum vitamin D levels $\geq 100 \mathrm{nmol} / \mathrm{L}$ [10], we call all responsible public health authorities to consider designating as the recommended dietary allowance (i.e., the average daily level of intake sufficient to meet the nutrient requirements of nearly all healthy people, presuming minimal sun exposure) intake levels corresponding to those proposed by the Endocrine Society Expert Committee (2011) as safe upper tolerable daily intake doses for patients at risk for vitamin $D$ deficiency
( $<50 \mathrm{nmol} / \mathrm{L}): 2000 \mathrm{IU}$ for those $<1$ year of age, $4000 \mathrm{IU}$ for those aged 1-18 years, and $10000 \mathrm{IU}$ for those aged $>18$ years.

Since $10000 \mathrm{IU} / \mathrm{d}$ is needed to achieve $100 \mathrm{nmol} / \mathrm{L}$ [9], except for individuals with vitamin $D$ hypersensitivity, and since there is no evidence of adverse effects associated with serum $25(\mathrm{OH}) \mathrm{D}$ levels $<140 \mathrm{nmol} / \mathrm{L}$, leaving a considerable margin of safety for efforts to raise the population-wide concentration to around $100 \mathrm{nmol} / \mathrm{L}$, the doses we propose could be used to reach the level of $75 \mathrm{nmol} / \mathrm{L}$ or preferably $100 \mathrm{nmol} / \mathrm{L}$. Of course, these recommended doses can be individualized based on dietary and sun exposure habits and the latitude of the country, and they can also be adjusted according to body mass index, age, and skin color, with obese, elderly, and darkskinned people needing higher doses.

\section{Explanation of the Pandemic of Vitamin D Deficiency}

Only $20 \%$ of our vitamin D reserve is meant to come from the diet. The remaining $80 \%$ is expected to be produced in our skin from the UV-B of the sun. In contrast to the context of the recommendations of the $1960 \mathrm{~s}$ of 4000 to $5000 \mathrm{lU} / \mathrm{d}$ to avoid rickets, our diet today is poor in wild fish $(\times 10$ richer in vitamin D), wild eggs, and fresh milk. Children are playing and people are working indoors all day long, and powerful sunprotective cosmetics are used to prevent melanoma. Even sunny countries such as Greece present a high prevalence of vitamin $D$ deficiency, as the angle of the sun rays from autumn to spring do not result in sufficient vitamin $D$ production with usual sun exposure.

\section{Optimal Vitamin D Supplementation}

With the target for vitamin $D$ set at $100 \mathrm{nmol} / \mathrm{L}$, the dose, frequency, and duration of supplementation will be important factors for healthy subjects committed to optimizing their nutritional status. Since in the case of vitamin $D$, serum levels depend on dietary intake (20\%) and sun exposure $(80 \%)$, a practical approach would be to recommend at least the threefourths of the upper tolerable dose proposed by the Endocrine Society to be taken as a supplement all year long except for circumstances such as vacations in which one engages in sunbathing. This could translate to, for instance, 1000 IU for children $<1$ year on enriched formula and $1500 \mathrm{IU}$ for those older than 6 months who are breastfed, 3000 IU for children $>1$ year of age, and up to $8000 \mathrm{IU}$ for young adults and thereafter, with non-pediatric doses adapted to the body mass index with the 
target set to $100 \mathrm{nmol} / \mathrm{L}$ instead of $50 \mathrm{nmol} / \mathrm{L}$. More importantly, according to the Endocrine Society's clinical practice guidelines, doses up to $1000 \mathrm{IU} / \mathrm{d}$ for infants up to 6 months, $1500 \mathrm{lU} / \mathrm{d}$ for infants from 6 months to 1 year, $2500 \mathrm{IU} / \mathrm{d}$ for children aged 1-3 years, $3000 \mathrm{IU} / \mathrm{d}$ for children aged 4-8 years, and $4000 \mathrm{IU} / \mathrm{d}$ for everyone over 8 years can be given safely without medical supervision just to prevent vitamin D deficiency, while higher doses may be needed to correct hypovitaminosis D.

\section{Importance of Vitamin D Supplementation}

Such a strategy relies on adequate supplementation among pregnant and lactating women, and on timely supplementation of every newborn before seroconversion towards autoimmune targets occurs. The benefits for individuals' general health status, apart from the obvious gains in skeletal health, cannot be fully foreseen, but may very well be surprisingly greater than expected given the impact of vitamin D deficiency on metabolic syndrome itself. Improvements in vitamin D status may help reduce the public health burden of metabolic syndrome and of potential subsequent health conditions, including type 2 diabetes and cardiovascular disease.

\section{CONCLUSION}

Unfortunately, medicine took a very long time to realize that vitamin $D$ is not simply a vitamin that prevents rickets. For that purpose, 400-600 IU/d may be enough. However, we know today that vitamin $D$ is a powerful nuclear receptor-activating hormone of critical importance, especially to the immune system. With the available data mentioned above, the proposed doses would probably suffice to maintain vitamin $D$ levels around or over $75-100 \mathrm{nmol} / \mathrm{L}$, with practically zero risk of toxicity. Undeniably, further studies are needed to clarify the optimal supplementation of vitamin $D$, although it is uncertain whether a universal recommended dietary allowance is feasible. Meanwhile, actions are urgently needed to protect the global population from the threats posed by vitamin D deficiency.

\section{CONFLICT OF INTEREST}

The author has no conflicts of interest associated with the material presented in this paper.

\section{ORCID}

Dimitrios T. Papadimitriou http://orcid.org/0000-0002-60833560

\section{REFERENCES}

1. Karvonen M, Pitkaniemi J, Tuomilehto J. The onset age of type 1 diabetes in Finnish children has become younger. The Finnish Childhood Diabetes Registry Group. Diabetes Care 1999; 22(7):1066-1070.

2. Makinen M, Simell V, Mykkanen J, Ilonen J, Veijola R, Hyoty $H$, et al. An increase in serum 25-hydroxyvitamin $D$ concentrations preceded a plateau in type 1 diabetes incidence in Finnish children. J Clin Endocrinol Metab 2014;99(11):E2353-E2356.

3. van Halteren AG, van Etten E, de Jong EC, Bouillon R, Roep BO, Mathieu C. Redirection of human autoreactive T-cells upon interaction with dendritic cells modulated by TX527, an ana$\log$ of 1,25 dihydroxyvitamin D(3). Diabetes 2002;51(7):21192125.

4. Hypponen E, Laara E, Reunanen A, Jarvelin MR, Virtanen SM. Intake of vitamin $D$ and risk of type 1 diabetes: a birth-cohort study. Lancet 2001;358(9292):1500-1503.

5. Papadimitriou DT, Marakaki C, Fretzayas A, Nicolaidou P, Papadimitriou A. Negativation of type 1 diabetes-associated autoantibodies to glutamic acid decarboxylase and insulin in children treated with oral calcitriol. J Diabetes 2013;5(3):344348.

6. Riek AE, Oh J, Darwech I, Moynihan CE, Bruchas RR, BernalMizrachi C. 25(OH) vitamin D suppresses macrophage adhesion and migration by downregulation of ER stress and scavenger receptor A1 in type 2 diabetes. J Steroid Biochem Mol Biol 2014;144 Pt A:172-179.

7. Kampmann U, Mosekilde L, Juhl C, Moller N, Christensen B, Rejnmark $L$, et al. Effects of 12 weeks high dose vitamin D3 treatment on insulin sensitivity, beta cell function, and metabolic markers in patients with type 2 diabetes and vitamin $D$ insufficiency: a double-blind, randomized, placebo-controlled trial. Metabolism 2014;63(9):1115-1124.

8. Veugelers PJ, Ekwaru JP. A statistical error in the estimation of the recommended dietary allowance for vitamin D. Nutrients 2014;6(10):4472-4475.

9. Heaney R, Garland C, Baggerly C, French C, Gorham E. Letter to Veugelers, P.J. and Ekwaru, J.P., A statistical error in the estimation of the recommended dietary allowance for vitamin D. 
Journal of

Preventive Medicine

The Big Vitamin D Mistake

\& Public Health

Nutrients 2014, 6, 4472-4475; doi:10.3390/nu6104472. Nutrients 2015;7(3):1688-1690.

10. Garland CF, Kim JJ, Mohr SB, Gorham ED, Grant WB, Giovan- nucci EL, et al. Meta-analysis of all-cause mortality according to serum 25-hydroxyvitamin D. Am J Public Health 2014;104 (8):e43-e50. 